\title{
NOTE
}

\section{Parallel growth patterns in algal epiphytes and Laminaria blades}

\author{
G. Russell \\ Hartley Botanical Laboratories, The University, Liverpool L69 3BX, England
}

\begin{abstract}
Sporophytes of the brown alga Laminaria saccharina were sampled from Menai Straits, N. Wales in April and December 1982. Discs of blade tissue were cultured for $4 \mathrm{wk}$ and the incidence and abundance of ectocarpoid epiphytes recorded. The patterns of distal increase in epiphytes proved indistinguishable in spite of seasonal differences in blade growth. This constancy of pattern indicates that the rates of epiphyte increase have followed closely those of their substrate. Synchronicity with the host blade should enhance epiphyte survival and increase the probability of particular host-epiphyte associations arising in nature.
\end{abstract}

Blades of Laminaria sporophytes serve as substrates for a number of epiphytic algae, among which certain members of the order Ectocarpales are particularly common. By culturing excised discs of blade tissue, it has been shown that epiphytes of $L$. digitata (Huds.)
Lamour. may colonize tissue of the transition zone between stipe and blade, and that their frequency and abundance increase distally, Russell (1983). The following observations concern seasonal aspects of ectocarpoid epiphyte development on blades of L. saccharina (L.) Lamour.

Sporophytes of Laminaria saccharina were collected from Menai Straits, North Wales on 27.4.82 and on 1. 12. 82. The former sample comprised plants which were passing through their period of rapid growth, while the latter were nearing the end of their slow phase, Parke (1948). The samples contained 26 and 25 plants respectively, all in their second year of life. A linear series of 25 equidistant discs, $3.8 \mathrm{~mm}$ in diameter, were punched from every blade. Each series began

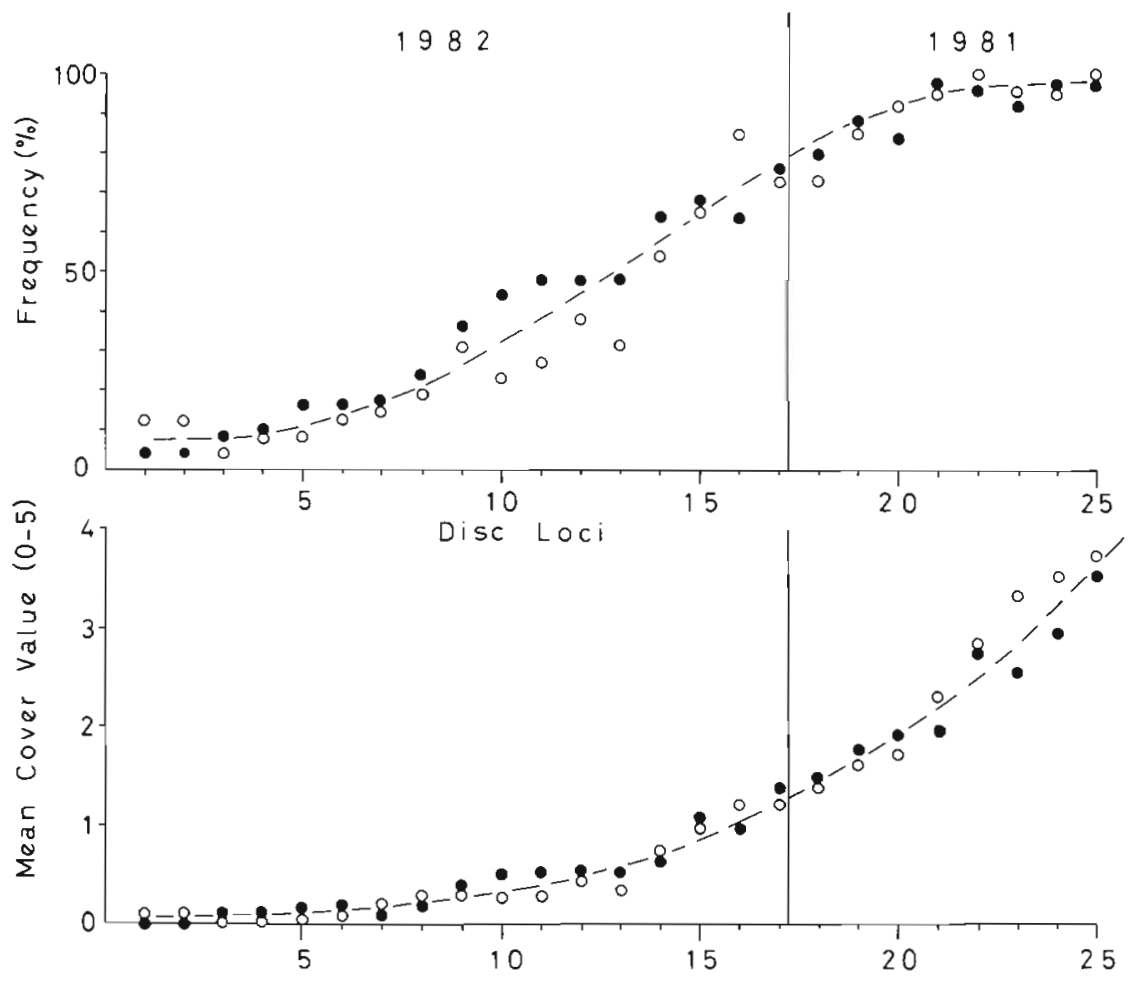

Fig. 1. Laminaria saccharina. Distal increase in frequency and cover of ectocarpoid epiphytes on cultured discs of blades. Open circles: host plants sampled in April 1982; closed circles: plants sampled in December 1982. Mean position of boundary between 1981 and 1982 blade tissues refers only to plants from April samples. Lines fitted by eye 
2 or $3 \mathrm{~cm}$ above the transition zone and terminated at a similar distance behind the distal tip of the blade. The relative positions of the disc loci were therefore comparable although interdisc distance varied with blade length. The discs were incubated in seawater culture medium for $4 \mathrm{wk}$ in order that any algal spores or microscopic stages present might attain visible size. The discs were cultured at $10^{\circ} \mathrm{C}$ under an irradiance of $11 \mathrm{~W} \mathrm{~m}^{-2}$ in $8: 16 \mathrm{~h}$ daylengths, as described by Russell (1983). After culturing, the discs were scanned under a low power microscope for the presence and abundance of ectocarpoid epiphytes, abundance being quantified using a 5-point scale of cover. Diatoms and multicellular algae belonging to other taxonomic groups were discounted.

The results (Fig. 1) agree closely with those reported for Laminaria digitata. The frequency of disc colonization showed little change between loci 1 to 5 , then increased more rapidly to virtually $100 \%$ in loci 20 to 25. The cover values of ectocarpoid algae also increased steadily along the blade.

All the plants in the April sample had retained portions of their 1981 blades, the mean position of the 1981-82 boundary being indicated on Fig. 1. The 1981 discs had been more often colonized than those of the 1982 tissue $\left(\chi^{2}=98.1 ; p<0.001\right)$ but the position of the boundary could not be associated with any obvious discontinuity in either frequency or cover (Fig. 1). The correlation coefficients between the April and December disc sets were significant $(p<0.001)$ for both attributes (Fig. 2).

It is evident that the epiphytes increased distally along the host blades in both samples, and at identical rates. Their pattern of seasonal growth and reproduction must therefore follow very closely the annual growth rhythms of their host, with the most rapid increase taking place during the first 6 mo of the year, and the slowest in the second. Synchronicity with the host plant should greatly enhance epiphyte survival

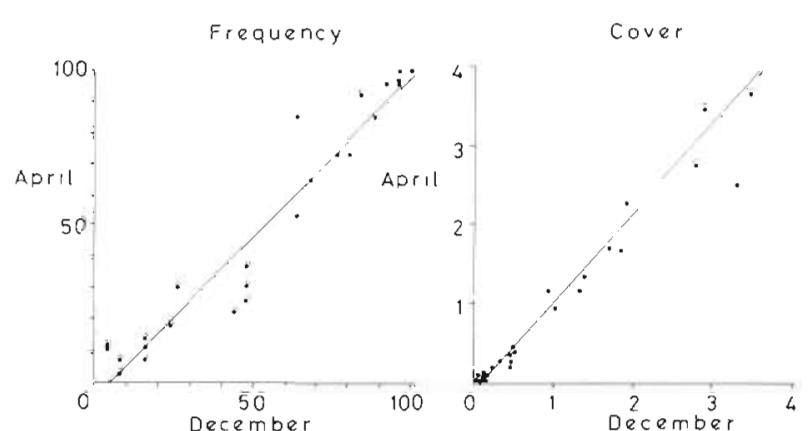

Fig. 2. Laminaria saccharina. Linear correlations between April and December disc sets in epiphyte frequency and cover. Slope of frequency regression line has the form $y=1.03 x-4.35$, the correlation coefficient being 0.967 $(p<0.001)$. Slope of cover regression line is $y=1.13 x-0.09$ the correlation coefficient being $0.985(\mathrm{p}<0.001)$

and increase the probability of particular species associations arising in nature.

The ectocarpoid algae present on the discs included Ectocarpus fasciculatus Harv., Giffordia granulosa (Sm.) Hamel, Punctaria sp. and Litosiphon filiformis (Reinke) Batt. The microthalli of these algae comprised the bulk of the disc epiflora, but species determinations depended upon the occasional formation of macrothalli.

Acknowledgements. I am grateful to Dr. W. E. Jones who collected Laminaria for me and to Mrs. G. M. Haynes who gave assistance in processing discs.

\section{LITERATURE CITED}

Parke, W. W. (1948). Studies on British Laminariaceae I. Growth in Laminaria saccharina (L.) Lamour. J. mar. biol. Ass. U. K. 27: 651-709

Russell, G. (1983). Formation of ectocarpoid epiflora on blades of Laminaria digitata. Mar Ecol. Prog. Ser 11: $181-187$

Accepted for printing on June 2, 1983 